\title{
AN INFORMAL FIELD STUDY OF SOME NEPENTHES HABITATS
}

Perry M. MAlouf, Ph.D • Bethesda, Maryland • USA • perry.malouf@ jhuapl.edu

Keywords: ecology: Borneo, Nepenthes -- field studies: Borneo, Nepenthes.

\section{Introduction}

An informal field survey of Nepenthes habitats (see Figures 1 and 2) was accomplished during four separate trips to the areas around Mount Kinabalu (Sabah, Malaysia, in 2001, 2004, 2006, and 2007) and around the city of Kuching (Sarawak, Malaysia, in 2006). Measurements were made of soil $\mathrm{pH}$ and soil conductivity. Observations were made of soil characteristics, relative humidity, light levels, and other flora located with the Nepenthes plants.

General descriptions of Nepenthes habitats were available in the literature before the present work was undertaken (Cheers 1993; Kurata 1976; Phillipps \& Lamb 1996; Pietropaolo \& Pietropaolo 1986). More recently, more detailed information was published about Nepenthes ecology (Clarke 1997, 2001). Various habitats are described, such as kerangas forests, peat swamps, montane forests, etc. Soils are described as infertile, with composition that varies widely with location (e.g., sandy peat, ultramafic clay).

As a Nepenthes hobbyist who has struggled to grow the plants well, I desired more quantitative information about Nepenthes habitats so that I could apply this knowledge to the cultivation of these amazing plants. Though my first trip to Mount Kinabalu was in 1994 (Malouf 1995a, 1995b) the survey was begun during a trip to the Mount Kinabalu area in 2001 and still continues as the author's resources (and physical stamina) allow. So far, the survey includes only areas around Mount Kinabalu in Sabah, Malaysia, and around the city of Kuching in Sarawak, Malaysia.

I admit that I am not a botanist; my training is in the physical sciences. I am competent in taking measurements and reporting the data, but my views of how the data relate to cultivation are based on personal experience as a hobbyist. If this paper encourages the publishing of corroborating and/or opposing viewpoints, then so much the better for information exchange.

\section{Data Collection and Measurement Methods}

At each study location I recorded date and time, latitude and longitude, altitude, temperature, relative humidity, and light level near the plant(s). A general description of the area was noted (e.g., forest floor, open hillside, etc.), along with the kinds of plants growing with the Nepenthes. One Nepenthes plant was selected for more specific study, and photographs of the plant were taken (see Figure 3). A gentle excavation of part of the root system was done so that the course of the roots through the soil strata could be photographed, and then a small volume of the soil from around the roots was taken for later analysis (see Figure 4). The root system was then re-packed in the soil. (Inspection of studied Nepenthes plants in succeeding years showed no detrimental effects from this procedure.) The soil samples were packed into plastic camera film canisters. Samples from a day's excursion were carried in a backpack at ambient temperature and then analyzed at the end of the day for $\mathrm{pH}$ and conductivity.

Measurement of light level was done with a Model 401025 light meter from Extech Instruments (Waltham, MA), serial number L568338. The instrument was configured for a slow response of the display. Ambient measurement conditions were noted (e.g., blue sky, overcast, shaded by canopy, etc.). Measurement of relative humidity was done with a calibrated sling 
psychrometer, model 12-7024 by Bacharach Corp. (Pittsburgh, PA). Ambient temperature was obtained from the dry bulb thermometer of the psychrometer. Latitude and longitude were obtained from a global positioning system receiver, the eTrex Vista from Garmin Corp. (Olathe, $\mathrm{KS}$ ); altitude was obtained from the barometric altimeter of the Vista. The altimeter was re-calibrated periodically at locations of known altitude.

Measurement of soil $\mathrm{pH}$ and soil conductivity was done with a $\mathrm{pH} /$ conductivity meter from Extech Instruments, model number 341350, used with a pH electrode model 60120B and a conductivity electrode (model number not available). Calibration of the $\mathrm{pH}$ electrode was done according to supplied instructions. Calibration standards of $\mathrm{pH} 4$ and $\mathrm{pH} 7$ were prepared in precision volumetric flasks using distilled water and standard buffer chemicals obtained from Micro Essential Laboratory (Brooklyn, NY). Calibration of the conductivity electrode was done with standard solution C1058 (Lot 990524, Anachemia Co., Rouses Point, NY), conductivity $1000 \mu$ Siemens $/ \mathrm{cm}$. All glassware used in the $\mathrm{pH}$ and conductivity measurements was washed with soap and water and then thoroughly rinsed in distilled water before use.

For $\mathrm{pH}$ and conductivity measurements, a 35-cc sample of soil was mixed with distilled water in the ratio of one part soil to two parts water by volume. This dilution ratio was chosen because the volume of added water was the minimum necessary to produce a solution that could be conveniently analyzed. This ratio is one of the most widely used in soil testing (Stefferud 1957). The mixture was thoroughly stirred and then allowed to stand for at least two hours. Afterwards, the $\mathrm{pH}$ electrode was immersed in the mixture until the meter reading stabilized and then the $\mathrm{pH}$ reading was recorded precise to the first decimal place. The $\mathrm{pH}$ electrode was removed and then the conductivity electrode was immersed in the mixture. The conductivity reading of the sample was recorded in $\mu$ Siemens $/ \mathrm{cm}$ with a precision of $10 \mu \mathrm{Siemens} / \mathrm{cm}$.

\section{Discussion}

Soil $\mathrm{pH}$ and Soil Conductivity

Table 1 contains a summary of the measurements of soil $\mathrm{pH}$ and soil conductivity, keyed to the plant where each soil sample was collected. Conductivity is given in $\mu S i e m e n s / \mathrm{cm}$.

The data confirm what has been stated in the referenced literature, that Nepenthes grow in soils that are acidic. (The case of $N$. northiana deserves further discussion and is presented in the next paragraph.) In some cases, the same species grows over a fairly wide range of soil $\mathrm{pH}$, e.g.,

\begin{tabular}{|c|c|c|c|c|c|}
\hline Species & $\mathrm{pH}$ & Conductivity & Species & $\mathrm{pH}$ & Conductivity \\
\hline N. albomarginata & 3.7 & 80 & N. northiana & $4.4-5.8$ & $20-50$ \\
\hline N. ampullaria & $4.5-5.0$ & $25-30$ & N. rafflesiana & $4.4-4.5$ & $20-30$ \\
\hline N. bicalcarata & 4.5 & $25-30$ & N. rajah & $5.6-6.0$ & $<10-40$ \\
\hline N. burbidgeae & $4.4-5.9$ & $<10-20$ & N. reinwardtiana & $4.2-6.6$ & $<10-40$ \\
\hline N. fusca & $4.2-5.0$ & $<10-70$ & N. stenophylla & $4.8-6.0$ & $<10-50$ \\
\hline N. gracilis & $3.8-5.6$ & $<10-70$ & N. tentaculata & $4.3-5.6$ & $<10-10$ \\
\hline N. hirsuta & 3.6 & 70 & N. villosa & $5.4-5.6$ & $<10$ \\
\hline N. lowii & $4.0-4.9$ & $<10-20$ & N. $\times$ alisaputrana & 4.7 & 20 \\
\hline N. mirabilis & $4.2-5.0$ & $<10-30$ & N. $\times$ kinabaluensis & $5.1-5.3$ & $<10$ \\
\hline \multicolumn{7}{|c|}{ Table 1. pH and conductivity of soils near root zone of listed Nepenthes } \\
\hline
\end{tabular}


$N$. reinwardtiana and $N$. stenophylla. The soils have a low conductivity, which suggests a low concentration of soluble ionic compounds (e.g., various salts). For comparison, my conductivity meter showed the conductivity of distilled water (no dissolved compounds whatsoever) to be 0-10 $\mu \mathrm{Siemens} / \mathrm{cm}$, the conductivity of rain water to be the same as distilled water, and the conductivity of my tap water at home to be about $300 \mu$ Siemens $/ \mathrm{cm}$. This last figure explains some of the trouble I had experienced in growing Nepenthes. The plants can suffer if their planting media accumulates dissolved salts introduced from the water.

Nepenthes northiana is known to grow on limestone hills, and limestone dissolved in water produces an alkaline solution $(\mathrm{pH}>7)$. At first glance it seems that this species grows in an alkaline medium and thus is at odds with the rest of the genus. It is important, however, to determine where the roots of the plant are growing, and to test the characteristics of the material surrounding the roots rather than assume the roots are growing in the limestone substrate. The plant considered in this study was in a dense forest and had roots that were surrounded by loose humus. A sample of the humus was tested and displayed the characteristics shown in Table 1. In a more open and exposed area, plants were seen growing on the surface of limestone tufa that had a thin coating of moss. The plants were not accessible so it was not possible to extract a sample of this mixture from around the roots. In a more accessible area that had no N. northiana, some scrapings of material similar in appearance were removed from the limestone and tested. This material had a $\mathrm{pH}$ of 7.1 and a conductivity of $280 \mu \mathrm{Siemens} / \mathrm{cm}$. It is not known for sure whether the tested material is the same as the material around the roots of the inaccessible $N$. northiana plants. It is certain, though, that the humus with the characteristics shown in Table 1 was collected from around the roots of a $N$. northiana plant.

In almost all of the observed habitats the underlying soil was covered with a layer of humus. In many cases, most of the Nepenthes roots were observed to grow into the humus layer while only a few tap roots entered into the underlying soil. The plants were found in soils with a wide range of compositions including underlying soils of ultramafic clay or sandy peat with humus on top, and soils of gravel covered with a thin mossy layer and no humus on top ("ultramafic" refers to minerals with high content of iron and magnesium).

\section{Relative Humidity}

The ideal study of relative humidity in Nepenthes habitats would have humidity meters in many different locations that would record the humidity constantly over the course of a year. Such an effort is beyond my capabilities. Instead I measured relative humidity just once at each of 48 locations where Nepenthes plants were found, in both mountain and lowland habitats. The measurements were made during the day between 9 a.m. and 5 p.m. Although this is not as thorough as the ideal study, it does indicate some clear trends. Table 2 summarizes the number of measurements falling within the indicated ranges of relative humidity.

\begin{tabular}{|c|c|c|c|c|c|c|c|c|}
\hline RH (\%) & 100 & $90-99$ & $80-89$ & $70-79$ & $60-69$ & $50-59$ & $40-49$ & $30-39$ \\
\hline \# of Measurements & 7 & 8 & 8 & 4 & 14 & 4 & 2 & 1 \\
\hline \multicolumn{10}{|c|}{ Table 2elative humidity measurements }
\end{tabular}

Readings of $100 \%$ relative humidity occur in the presence of rain or drizzle. These readings can be neglected if we are interested in the relative humidity when it is not raining in the habitat. In that case, the data show a clear trend for relative humidity between $60 \%$ and $69 \%$. The number of samples drops off sharply for lower values of relative humidity. There is another concentration of readings between $80 \%$ and $99 \%$. This may be due to the fact that many of the studied habitats were in cloud forest areas (montane habitat) where fog was present, so these measurements might not apply to lowland habitats.

\section{Light Level}

Obviously, the amount of light available to a plant is a function of the surrounding vegetation 
as well as weather conditions. I observed Nepenthes under a dense forest canopy where the light levels on a sunny day reached only 3230 lux. I have observed others on open hills where the light levels on a sunny day reached 53,580 lux. Some literature describes Nepenthes as not inhabiting dense forests but preferring forest edges where more light is available (Steiner 2002). I have observed similar situations, but this does not tell the entire story (see below).

\section{Growth of Nepenthes and Companion Plants over Time}

The measurements of soil $\mathrm{pH}$ and conductivity have already been presented as fairly constant for a given habitat, things that do not change with the time of day or season of the year. Relative humidity is also somewhat constant, in that it is almost always humid in a Nepenthes habitat. Light levels are not so constant over the life cycle of Nepenthes, being affected by how other plants grow alongside. The appearance of a Nepenthes habitat changes substantially over time as Nepenthes progress from seedlings to adult plants. Nepenthes are pioneer plants that are among the first to start growing in an area that has been disturbed somehow (e.g., landslide, forest fire, earth-moving equipment). After such a disturbance, the soil is bare and the area is often completely exposed to the sun. I have seen Nepenthes seedlings in such an environment. Nearby, adult plants of the same species were found in a habitat that included a lot of vegetation that had grown taller than the Nepenthes in many cases and was providing a lot of shade. When one observes mature Nepenthes plants in habitat, and tries to derive cultivation information from these observations, it is important to realize that the habitat may have been quite different when the Nepenthes first began to grow.

A good example of how the habitat changes as the Nepenthes mature is the kerangas forests around Kuching. These undergo periodic disturbances, such as fire, that leave an area bare and open. In places where vegetation begins growing again in the sandy peat, it is still mostly bare with a few shrubs about waist high and the occasional Nepenthes seedling. It is very open and sunny in these areas. Nearby, the undisturbed kerangas forest has tall trees, with large specimens of $N$. rafflesiana and $N$. bicalcarata climbing 4-5 $\mathrm{m}$ up the tree trunks. The shrubs found in the open areas are actually saplings of the same tall tree species found in the undisturbed areas (Ch'ien Lee, pers. comm.). This situation may explain why at least one author (Steiner 2002) describes adult plants preferring forest edges. In kerangas forest, the Nepenthes seedlings start side by side with the tree saplings and both grow up together. Once an area in the forest is cleared by fire, there are bound to be adult Nepenthes plants growing in the edges of the undisturbed forest around the cleared area.

For some of the slow-growing species, like $N$. burbidgeae, the habitat can change a lot as the Nepenthes mature. I have seen $N$. burbidgeae plants, whose stems under the dense forest canopy appeared to be small tree trunks as thick as my arm, climbing $9 \mathrm{~m}$ to the tree tops where the plants finally ended in a flourish of leaves and upper pitchers. I suspect that these mature plants are many decades old, so the surrounding plants had time to grow quite tall. Not far away, large basal rosettes could be found in more open areas. Seedlings were almost always in areas that were relatively clear except for some grasses.

Nepenthes gracilis grows much faster than $N$. burbidgeae, but the habitat progression is still similar. Adult $N$. gracilis plants were found near abandoned farming areas (abandoned probably because the soil was too poor to grow crops). The plants were $2 \mathrm{~m}$ tall in some cases and were growing through grass and shrubs of the same height. It is easy to imagine that the $N$. gracilis plants began to grow after the area had been cleared for farming. The seedlings would have been exposed to a lot of sun. Other grasses and shrubs grew alongside the seedlings so that the plants were intertwined when I finally observed them.

In soils that are more fertile, it is possible that the Nepenthes may begin growing but ultimately are crowded out by plants that can grow much faster in the better soil. I observed this on repeated trips to a location near Mount Kinabalu. During the first trip in 2004, a steep gravel hillside had many plants of $N$. stenophylla, $N$. fusca, and $N$. reinwardtiana. Some of them were large adult plants, others were seedlings of these plants and of their various hybrids. The rest of the hillside had some scattered clumps of grasses and moss on the otherwise bare gravel. In 2007 this same 
hillside was covered with thick tall grass, so thick as to make it very difficult to walk into the growth. Not a single Nepenthes plant was observed there. The fact that there were adult plants on the hillside in 2004 suggests that the conditions were favorable for Nepenthes for several years, long enough for seedlings to grow to adulthood. Nevertheless, the conditions were also favorable enough for some grasses to completely overgrow the area and crowd out the Nepenthes by 2007. This site does not have public access, and a nearby hillside still had plenty of Nepenthes plants, so I doubt that the Nepenthes were poached.

\section{Flora Found with Nepenthes in Habitat}

Table 3 contains a listing of some plants found growing with Nepenthes in habitat, segregated according to altitude. For each altitude zone, the plants are further segregated into their various types. It is interesting that some plants are commonly found alongside Nepenthes across most of the altitude zones: Gleichenia sp., Blechnum sp., Imperata cylindrica, Miscanthus sp., and Lycopodium sp.

\begin{tabular}{|c|c|}
\hline Altitude (m) & Plants \\
\hline $0-305$ & $\begin{array}{l}\text { Trees and shrubs: Cratoxylum arborescens, Ploiarium alternifolium, Dillenia suffruticosa, } \\
\text { Dipterocarpus sp., Shorea sp.; Orchids: Arundina graminifolia, Bromheadia sp., Bulbophyllum } \\
\text { sp., Paphiopedilum stoneii; Ferns: Gleichenia sp.; Others: Alocasia longiloba, Begonia sp., } \\
\text { Lycopodium sp. }\end{array}$ \\
\hline $305-610$ & $\begin{array}{l}\text { Trees and shrubs: Nauclea sp., Tristaniopsis sp.; Ferns: Blechnum sp., Gleichenia sp.; } \\
\text { Grass: Imperata cylindrical; Others: Lycopodium sp., Melastoma sp. }\end{array}$ \\
\hline $610-915$ & $\begin{array}{l}\text { Trees and shrubs: Adinandra sp., Gymnostoma sp.; } \\
\text { Ferns: Gleichenia sp.; Grass: Miscanthus sp. }\end{array}$ \\
\hline $915-1220$ & $\begin{array}{l}\text { Trees and shrubs: Ficus sp., Macaranga sp.; Grass: Imperata cylindrica, Miscanthus sp.; } \\
\text { Ferns: Pteridium sp.; Others: Melastoma sp. }\end{array}$ \\
\hline $1220-1525$ & $\begin{array}{l}\text { Trees and shrubs: Crotalaria sp., Gymnostoma sp., Macaranga sp., Nauclea } \mathrm{sp} . \text { Vaccinium } \mathrm{sp} . ; \\
\text { Grass: Miscanthus sp.; Orchids: Arundina graminifolia; Ferns: Blechnum sp., Pteridium sp.; } \\
\text { Others: Lycopodium sp., Melastoma sp. }\end{array}$ \\
\hline $1525-1830$ & $\begin{array}{l}\text { Trees and shrubs: Adinandra sp., Nauclea sp., Phyllocladus sp.; Orchids: Arundina graminifolia, } \\
\text { Coelogyne sp., Spathoglottis sp.; Ferns: Gleichenia sp.; Grass: Miscanthus sp.; } \\
\text { Others: Lycopodium sp., Melastoma sp. }\end{array}$ \\
\hline $1830-2135$ & $\begin{array}{l}\text { Trees and shrubs: Agathis sp., Dacrydium sp., Leptospermum sp., Phyllocladus sp., Vaccinium } \\
\text { sp.; Orchids: Coelogyne sp.; Ferns: Blechnum sp., Gleichenia sp.; Grass: Juncus sp., Miscanthus } \\
\text { sp.; Others: Hedyotis sp., Lycopodium sp., Melastoma sp. }\end{array}$ \\
\hline $2135-3050$ & $\begin{array}{l}\text { Trees and shrubs: Dacrydium sp., Leptospermum sp., Phyllocladus sp., Styphelia sp., } \\
\text { Vaccinium sp.; Orchids: Coelogyne sp., Trichotosia sp.; Others: Hedyotis sp., Iridaceae sp. }\end{array}$ \\
\hline & Table 3. Listing o \\
\hline
\end{tabular}

\section{Field Observations Applied to Cultivation}

In applying the above observations to the cultivation of Nepenthes, I follow the common-sense rule that the plants will thrive in cultivation if they are given what they enjoy in their native habitat.

The composition of the soil is not as important as the $\mathrm{pH}$ and conductivity of the mix. No matter what potting media used, it is important for the $\mathrm{pH}$ to be acidic, and for the conductivity to be as low as possible. It is also important to provide water that is free from dissolved salts and other chemicals or else a potting medium that starts out with low conductivity could accumulate salts and the soil conductivity will rise. A plant that has been repotted in a proper soil and is growing vigorously will begin to suffer after several months as the conductivity of the soil increases, which makes salt accumulation a very 

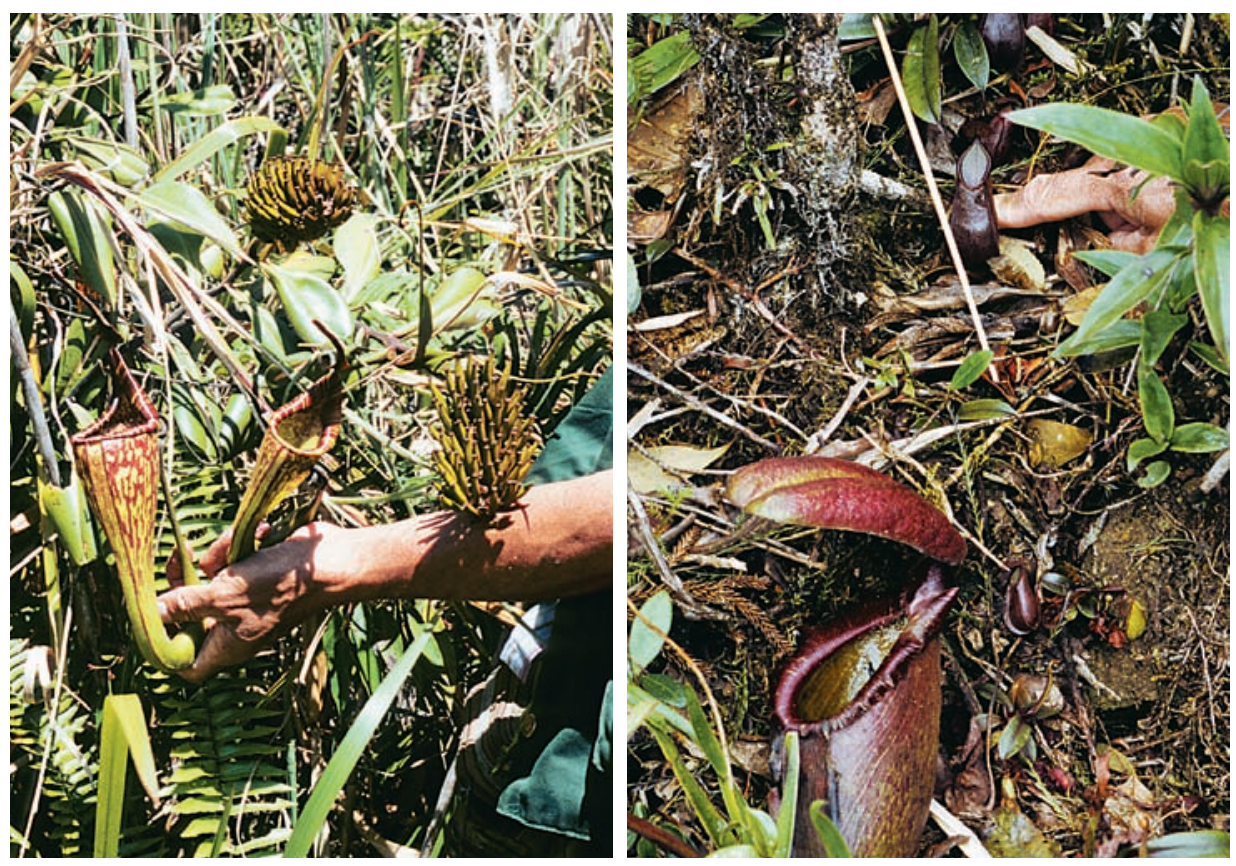

Figure 1: Nepenthes fusca with seed pods. Figure 2: Nepenthes rajah and Nepenthes tentaculata in the wild.

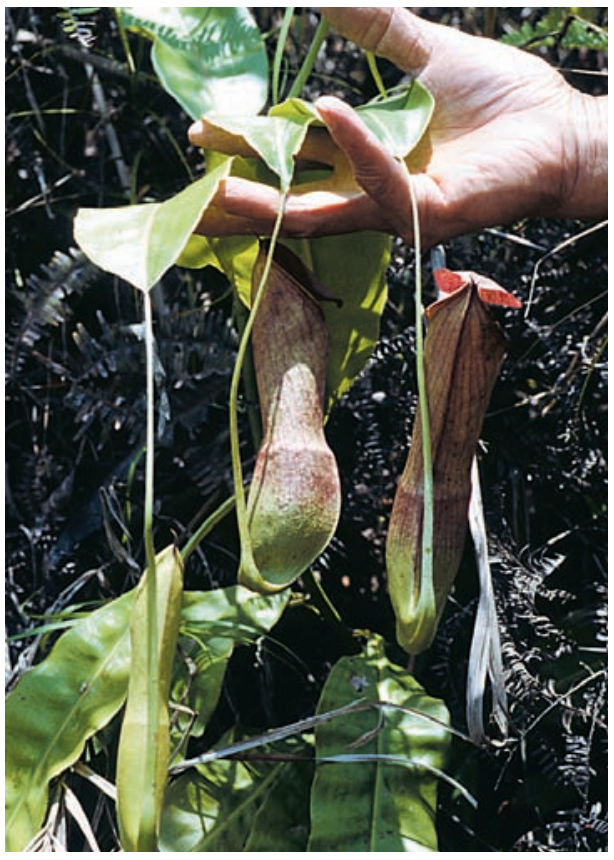

Figure 3: Nepenthes mirabilis pitchers.

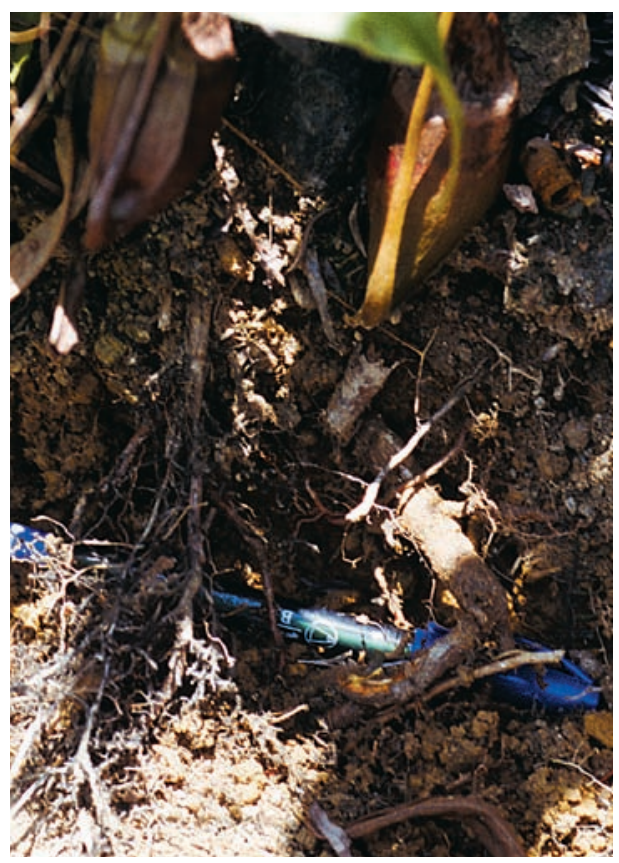

Figure 4: The partially excavated root system of Nepenthes mirabilis. Blue pen for scale comparison. 
sneaky problem. Some growers are lucky enough to have plenty of available rain water, or other sources of very pure water. Most urban areas have treated water that is not very good for Nepenthes over time. (Remember, Nepenthes in habitat get rain water.) One final note about potting media - if in doubt about your mix, have the $\mathrm{pH}$ and conductivity tested. One grower told me he used coconut husk successfully until he changed suppliers. The new supplier rinsed the coconut husk in sea water! Needless to say, Nepenthes plants did not grow well at all in this salty coconut husk.

Nepenthes enjoy a constant relative humidity between $60 \%$ and $70 \%$. Sometimes the humidity does drop to $45 \%$ in habitat but it does not stay there for long. Relative humidity in a greenhouse is linked to temperature, decreasing with increasing temperature and vice versa. Temperature is typically highest during the day and coolest at night, so humidity tends to be highest at night and lowest in the day. Some means of humidity replenishment during the heat of the day is a good idea for cultivating Nepenthes. The best temperature for the plants will depend on whether the natural habitat is on the cool side (e.g., upper montane areas, cloud forests) or very hot (e.g., lowland kerangas forests).

Light for cultivating Nepenthes is a complicated subject, especially if artificial lighting is considered, and the topic deserves a separate article. Since Nepenthes in their habitat get sunlight, it stands to reason that artificial lighting should be as close as possible to the solar spectrum. In contrast to this, fluorescent lights have been used with some success even though they have a spectrum that is quite different from the solar spectrum. As for light level, this varies widely in the field even for the same species. The only general trend is that seedlings are often found in open areas that are exposed to strong light on clear sunny days. Sometimes adult plants are found in these conditions. More often, though, adult plants are found growing among other plants that provide shade (and sometimes this shade is substantial).

Plants that are given what they enjoy in habitat should thrive in cultivation. If the soil conductivity or soil $\mathrm{pH}$ is a bit high, or the humidity is a bit low and inconsistent, then the plants may survive but they will neither thrive nor look their best.

Acknowledgements: The following individuals, listed in alphabetical order, provided helpful comments or other assistance in the preparation of this paper: Anthony Lamb, Ch'ien Lee, Dr. Pitt Kent Lim, Anthea Phillipps, Robert Sacilotto. I am deeply indebted to certain individuals among the local population living in the foothills of Mount Kinabalu for their invaluable assistance and guidance while trekking through the forest, and for introducing me to the charming native peoples and culture of the area. No special permits were required to visit the sites described in this paper.

\section{References}

Cheers, G. 1992. A Guide to Carnivorous Plants of the World. Harper Collins Publishers, Pymble NSW 1993, Australia, pp. 141-142.

Clarke, C. 1997. Nepenthes of Borneo. Natural History Publications (Borneo) Sdn. Bhd., Kota Kinabalu, Sabah, Malaysia. pp. 23-32.

Clarke, C. 2001. Nepenthes of Sumatra and Peninsular Malaysia. Natural History Publications (Borneo) Sdn. Bhd., Kota Kinabalu, Sabah, Malaysia. pp. 29-40.

Kurata, S. 1976. Nepenthes of Mount Kinabalu, Sabah National Parks Trustees, Kota Kinabalu, Sabah, Malaysia. pp. 21-24.

Malouf, P. 1995a. A visit to Kinabalu Park. Carniv. Pl. Newslett. 24: 64-69.

Malouf, P. 1995b. A visit to Kinabalu Park. Carniv. Pl. Newslett. 24: 104-108.

Phillipps, A., and Lamb, A. 1996. Pitcher-Plants of Borneo. Natural History Publications (Borneo) Sdn. Bhd., Kota Kinabalu, Sabah, Malaysia. pp. 43-45.

Pietropaolo, J., and Pietropaolo, P. 1986. Carnivorous Plants of the World. Timber Press, Portland, Oregon. p. 40.

Stefferud, A. (ed.) 1957. The Yearbook of Agriculture. USDA, Washington, DC. p. 188.

Steiner, H. 2002. Borneo Its Mountains and Lowlands with their Pitcher Plants. Toihaan Publishing Company Sdn. Bhd., Kota Kinabalu, Sabah, Malaysia. p. 31. 